fully implanted or not, then my specimen is not so far advanced in this respect as the $W i-8004$ ovum, in that no surface epithelialization has yet commenced in iny specimen, but the embryonic tissues are separated from the uterine cavity by the maternal fibrinous elements of the operculum. This process of epithelialization evidently takes a considerable time, since it is not complete even in the $11 \cdot 5$ - and 12.5-day Hertig-Rock ova ${ }^{2}$, by which time the "fullyimplanted" ovum has undergone considerable advance in development beyond the stage shown in my specimen.

But such trivialities mask the important principle that the various elements in human ova of approximately the same age may show considerable differences in the stage of development which they have attained; such has been shown also in macaque embryos by Heuser and Streeter $^{3}$. Whereas the general organization of my specimen is similar to that of the 9-5-day Rock-Hertig ovum ( $W i-8004)$, some features of the latter are more developed (for example, partial surface epithelialization, two-layered endoderm), and some are less developed (for example, total size of ovum, thickness of trophoblast) than in my specimen. I have discussed the above points fully in a paper I have submitted for publication elsewhere.

I therefore still maintain that "these two ova represent the earliest specimens of fully implanted human ova yet discovered", and that the detailed differences between them are compatible with their being approximately the same age. I naturally share the admiration of Profs. Hamilton and Boyd for the work of Rock and Hertig.

Department of Anatomy,

University, Sheffield, 10.

${ }^{1}$ Rock, J., and Hertig, A. T., Amer. J. Obstet. Gynecol., 44, 973 (1942). ${ }^{2}$ Hertig, A. T., and Rock, J., Contrib. Embryol. Carnegie Inst. Wash., 29, No. 184, 127 (1941).

- Heuser, C. H., and Streeter, G. L., Contrib. Embryol. Carnegie Inst. Wash., 29, No. 181, 15 (1941).

\section{Display and Bower-building in Bower-birds}

As investigation was carried out on the fairly typical bower-bird, Ptilinorhynchus violaceus, during 1939-41 in the Zoology Department of the University of Sydney and in rain-forests of eastern Australia. A full report of the investigation is at present in the Fisher Likrary in the University. The War having interfered with publication, the general conclusions reached are summarized below.

(1) The annual cycle of display and bower-building is dependent on the gonads and is stimulated by the same environmental factors that initiate actual breeding in other birds of the locality. Increasing light may be the principal stimulus ; food and temperature have nothing to do with it.

(2) The male has already selected, or has been selected by, his mate when he arrives at his bowerterritory after leaving the off-season feeding-flock in July. Thus bowers and decorations have little to do with sexual selection, which may have taken place during the winter flocking. It seems that the primary function of display and its associated specializations (bower, colour, 'decorations', noise, etc.) is to stimulate male and female reproductive systems as a prelude to successful fertilization. It is probable that external stimuli from the bower, etc., pass through visual and auditory receptors to the central nervous system and thence through the anterior pituitary to the gonads. Gonadectomy inhibits bower-construction and display. (Attempts to remove the anterior pituitary ended fatally.)

(3) Display and decoration of the bower begin in July-August : it is not until September-October that nesting begins.

(4) In the selection of its coloured 'decorations' or playthings the male Ptilinorhynchus closely matches the colours, especially the conspicuous epigamic features, of the female. During male display the female takes little or no active part-she may be absent or impassively present. The male's colour choices (blue, lemon-yellow and grey-brown) may serve the function of exciting himself by their resemblance to female colours.

(5) Some male birds paint or plaster the inner walls of their bowers with fruit-pulp, macerated wood or charcoal and other substances. The habit of painting coincides with that of breeding and not that of display.

(6) At least one species of bower-bird (Ptilinorhynchus), probably a second (Chlamydera cerviniventris) and possibly a third orientate their bowers across the sun's path.

(7) When the female leaves the bower-territory in September-October, she alone begins nidification and incubation, often in a part of the forest distant from the bower. The male continues his display without an audience and with undiminished vigour. This continues almost without interruption until January, when the female and her young arrive at the bower and a communal display takes place. In a few weeks, or days, the bower is deserted or wrecked, and the family party joins one of the large gregarious feeding flocks which are moving noisily through the fruitbearing trees of the forest. In these flocks, numbering from ten to a hundred, a minor form of display is constantly taking place. The family parties are broken up in the feeding flocks.

\section{2/2 Aust. Inf. Bn., A.I.F., Australia.}

A. J. Marshall.

\section{A Simple Technique for Photomicrography}

DR. LEAK's article in Nature of May 6 has interested me very much; it describes a procedure which I think I was responsible for 35 years ago when I was working at Santa Elena in Entre Rios, Argentina.

I had an early Leitz microscope, and was interested in Texas cattle fever, blackwater and other trypanosome diseases. I had a good Kodak camera, and I also had a very early Kodak 'Brownie' camera making pictures on roll film about $2 \frac{1}{4}$ in. by $2 \frac{1}{4}$ in.price 5s.-without view-finder. This little camera was so small and easily balanced that I found it unnecessary to do more than set up the microscope with the optical axis vertical, focus the object as for ocular observation as accurately as might be, and simply place the camera on the eyepiece, which was large enough to hold it quite safely without any other support, centring the lens by judgment and opening the shutter as smoothly as I could. I used a Welsbach mantle gas burner for the illumination.

Most of the pictures I took at that time were equal to anything I have taken since, even with very much more elaborate and expensive equipment. Unfortunately, I have preserved no prints or films.

9 The Wiend, Bebington, J. LEONARD Bowen. 